\title{
MerTK-mediated regulation of myelin phagocytosis by macrophages generated from patients with MS
}

\section{OPEN}

Luke M. Healy, $\mathrm{PhD}$

Jeong Ho Jang So-Yoon Won

Yun Hsuan Lin

Hanane Touil

Salman Aljarallah, MD

Amit Bar-Or, MD

Jack P. Antel, MD

Correspondence to

Dr. Healy:

luke.healy@mcgill.ca

\section{ABSTRACT}

Objective: To document functional differences between monocyte-derived macrophages (MDMs) of patients with MS and the ability of age/sex-matched healthy donor cells to phagocytose human myelin and to investigate the molecular mechanisms that underlie this.

Methods: MDMs were derived from peripheral blood monocytes of 25 untreated patients with relapsing-remitting MS and secondary progressive MS and age/sex-matched healthy controls (HCs). Phagocytosis was assessed by flow cytometry using fluorescently labeled human myelin. Quantification of messenger RNA and protein expression of Tyro3, Axl, and MerTK family molecules was determined by quantitative PCR, Western blotting, and flow cytometry.

Results: Cells of patients with MS display a reduced ability to phagocytose human myelin but not red blood cells as compared to matched HCs. These cells express significantly lower levels of the phagocytic tyrosine kinase receptor, MerTK, and its natural ligand, growth arrest-specific 6, independently of the activation state of the cells. Increased expression of interleukin 10 following myelin uptake by healthy donor cells is lost in MDMs of patients with MS; this effect is mediated through the MerTK pathway. Treatment of MS cells with transforming growth factor $\beta$ (TGF $\beta$ ) restored both phagocytosis and expression deficits.

Conclusions: We describe a molecular mechanism that underlies a defect in myelin phagocytosis by macrophages generated from patients with MS. This abnormality involves decreased expression of MerTK and its ligands and can be rescued by treatment with TGF $\beta$. Neurol Neuroimmunol Neuroinflamm 2017;4:e402; doi: 10.1212/NXI.0000000000000402

\section{GLOSSARY}

FBS = fetal bovine serum; Gas6 = growth arrest-specific 6; HC = healthy control; IL-10 = interleukin 10; MDM = monocyte-derived-macrophage; $\mathbf{m R N A}=$ messenger RNA; PBS = phosphate-buffered saline; PPAR- $\boldsymbol{\gamma}=$ peroxisome proliferatoractivated receptor gamma; ProS = protein S; PS = phosphatidylserine; $\mathbf{R B C}=$ red blood cell; $\mathbf{R R M S}=$ relapsing-remitting MS; $\mathbf{R X R}=$ retinoid $\mathbf{X}$ receptor; $\mathbf{S P M S}=$ secondary progressive $\mathrm{MS} ; \mathbf{T A M}=\mathrm{Tyro3}, \mathrm{Axl}$, and MerTK; $\mathbf{T G F} \boldsymbol{\beta}=$ transforming growth factor $\beta$.

Clearance of myelin debris following CNS tissue injury in MS is required for subsequent tissue repair. ${ }^{1}$ Myeloid cells within MS lesions capable of phagocytosis include both microglia and macrophages that are derived from circulating monocytes. ${ }^{2-4}$ We previously observed that the tyrosine kinase receptor, MerTK, a member of the TAM (Tyro3, Axl, and MerTK) family of tyrosine kinase receptors, is important in mediating myelin phagocytosis by human myeloid cells. ${ }^{5}$ MerTK expression correlated with increased phagocytosis and was dependent on the myeloid cell activation state, with transforming growth factor $\beta$ (TGF $\beta$ ) enhancing expression of the TAM family receptors and pro-inflammatory cytokines decreasing their expression. ${ }^{5}$ Myeloid cell-mediated myelin phagocytosis was inhibited in vitro by selective MerTK antagonism. ${ }^{5}$

\footnotetext{
From the Neuroimmunology Unit (L.M.H., J.H.J., S.-Y.W., Y.H.L., H.T., S.A., A.B.-O., J.P.A.), Montreal Neurological Institute and Hospital, McGill University, Montreal, Quebec, Canada; and Multiple Sclerosis Division (A.B.-O.), Department of Neurology and Center for Neuroinflammation and Neurotherapeutics, Perelman School of Medicine, University of Pennsylvania, Philadelphia.

Funding information and disclosures are provided at the end of the article. Go to Neurology.org/nn for full disclosure forms. The Article Processing Charge was funded by the authors.

This is an open access article distributed under the terms of the Creative Commons Attribution-NonCommercial-NoDerivatives License 4.0 (CC BY-NC-ND), which permits downloading and sharing the work provided it is properly cited. The work cannot be changed in any way or used commercially without permission from the journal.
} 
TAM receptors mediate their action via their 2 natural ligands, growth arrest-specific 6 (Gas6) and protein S (ProS). Receptorbound Gas6 and ProS concurrently bind to phosphatidylserine (PS), a phospholipid, exposed on the outer membrane of apoptotic cells. ${ }^{6,7}$ PS is also found in lipid-rich myelin. ${ }^{8}$ Both receptors and ligands are needed for efficient phagocytosis. ${ }^{9}$ TAM receptor signaling is implicated in regulating inflammation because deficiencies in signaling have been associated with sustained immune activation and chronic inflammation. ${ }^{10}$ Recently identified and characterized polymorphisms in the MerTK gene have established MerTK as a novel risk gene for MS susceptibility. ${ }^{11,12}$

A recent study demonstrated that peripheral blood monocyte-derived macrophages (MDMs) of patients with MS display impaired myelin phagocytosis and an enhanced proinflammatory phenotype. ${ }^{13}$ In the current study, we confirm that MDMs of patients with MS are functionally abnormal in their ability to phagocytose and that this deficit is relatively selective to myelin. This functional deficit is linked to altered MS myeloid cell expression of MerTK and its ligands, where both expression and functional deficits can be subsequently rescued by exposure to the TGF $\beta$. Our results indicate that the TAM receptor-signaling axis may be amenable to the therapeutic intervention.

METHODS Standard protocol approvals, registrations, and patient consents. All institutional ethics approval was obtained according to Canadian Institutes of Health Research guidelines. All patients provided written informed consent in accordance with the Declaration of Helsinki, and approval was obtained from the Institutional Review Board of McGill University.

Patient selection. A total of 25 patients with MS (18 relapsingremitting MS [RRMS] and 7 secondary progressive MS [SPMS]) were recruited at the Montreal Neurological Hospital MS Clinic (figure 1A). Of the 18 patients with RRMS in this study, treatment history was as follows: treatment naive (7), Copaxone (5), Gilenya (2), Avonex (1), Rebif (2), and Tecfidera (1). All patients had a minimum 3-month washout period prior to contributing to this study, and we did not observe any difference between treatment-naive patients and those currently off drug. Healthy age- ( \pm 5 years) and sex-matched controls were used for comparison.

Cell culture (human MDMs). Peripheral blood mononuclear cells were isolated from the venous blood using Ficoll-Paque density gradient centrifugation (GE Healthcare). Monocytes were positively selected using $\mathrm{CD} 14^{+}$immunomagnetic beads (according to manufacturer's instructions; Miltenyi Biotec, Bergisch Gladbach,
Germany) to routinely achieve $95 \%-99 \%$ purity. Monocytes were cultured $\left(5 \times 10^{5}\right.$ cells $\left./ \mathrm{mL}\right)$ in Roswell Park Memorial Institute 1640 media supplemented with $10 \%$ fetal bovine serum (FBS), $0.1 \%$ penicillin/streptomycin, and $0.1 \%$ glutamine. MDMs were differentiated in vitro with macrophage-colony stimulating factor ( 25 $\mathrm{ng} / \mathrm{mL})$ for 6 days. For select experiments, TGF $\beta(20 \mathrm{ng} / \mathrm{mL})$ was added on days 1 and 5 .

Phagocytosis assay. Endotoxin-free human myelin was prepared as previously described. ${ }^{14}$ To evaluate myelin phagocytosis, MDMs were plated in 12-well plates. ${ }^{5}$ Myelin was conjugated to a $\mathrm{pH}$-sensitive dye ( $\mathrm{pH}$-Rodamine; Invitrogen, Carlsbad, CA) for 1 hour in phosphate-buffered saline (PBS) ( $\mathrm{pH} 8)$ and added to the culture wells $(20 \mu \mathrm{g} / \mathrm{mL})$ for 1 hour; cells were washed, detached, pelleted, and passed through a flow cytometer (FACS Fortessa; BD Biosciences, San Jose, CA) to quantify the percentage of myeloid cells containing internalized fluorescent myelin. A similar protocol was used to study phagocytosis of red blood cells (RBCs) acquired from FicollPaque density gradient centrifugation and diluted in PBS at a ratio of 1:2,500. RBCs were then incubated with opsonizing antibody $(20 \mu \mathrm{g} / \mathrm{mL}$ : Cederlane) and $\mathrm{pH}$-rhodamine for 30 minutes at room temperature. MDMs were exposed to opsonized RBCs for 1 hour at a 4:1 (RBC:MDM) ratio, and internalized RBCs were quantified as an increase in mean fluorescent intensity in the PE channel.

Quantification of TAM receptor/ligand and cytokine mRNA expression. Cells were lysed in TRIzol reagent (Invitrogen) and stored at $-80^{\circ} \mathrm{C}$. Total RNA extraction and reverse transcription were performed according to manufacturer's instructions (Qiagen, Hilden, Germany). Individual gene expression was analyzed by PCR using specific TaqMan probes to assess expression relative to Gapdh (housekeeping gene). Fold change calculations were done using the $-\Delta \Delta$ threshold cycle method.

Quantification of protein expression. For quantitation of MerTK protein expression, MDMs were detached using EDTA/PBS $(2 \mathrm{mM})$. Cells were blocked in $10 \%$ normal human serum and normal mouse immunoglobulin $\mathrm{G}(3 \mathrm{ng} / \mathrm{mL})$ in fluorescence-activated cell sorting buffer (1\% FBS in PBS), incubated with anti-MerTK antibody or concentration-matched antigen-presenting cell-conjugated isotype antibody (FAB8912A; R\&D Systems, Minneapolis, MN), and analyzed by flow cytometry (FACS Fortessa; BD Biosciences). Myeloid cells were gated based on the side scatter area and forward scatter area.

Western blotting Polyvinylidene difluoride membranes were probed with anti-TGFßR1 antibody (polyclonal rabbit anti-human antibody 1:5,000; Abcam, Cambridge, United Kingdom) and detected using horseradish peroxidase-conjugated secondary antibodies (1:1,000; Calbiochem, San Diego, CA). Membranes were stripped with ReBlot (Millipore, Billerica, MA) and re-probed for loading control (anti- $\beta$-actin; 1:1,000; Invitrogen). Protein band intensities were quantified using ImageJ software $(\mathrm{NIH})$, and data were expressed as relative fold change to untreated controls.

Results MDMs of patients with MS exhibit abnormally reduced phagocytosis of human myelin (but not RBCs), which can be restored by TGF $\beta$. A lower percent of MS (both RRMS and SPMS) patient-derived MDMs phagocytosed myelin compared with their matched healthy controls (HCs) (figure 1C). TGF $\beta$ treatment increased myelin phagocytosis in both HCs and RRMS MDMs to levels that were no longer 


\section{A. Demographics}

\section{Control:}

$\mathrm{n}=25$

Sex ratio $F: M=16: 9$

Mean age $+/-$ SD

$=42.3 \pm 14.3$

Range $=24-69$
B
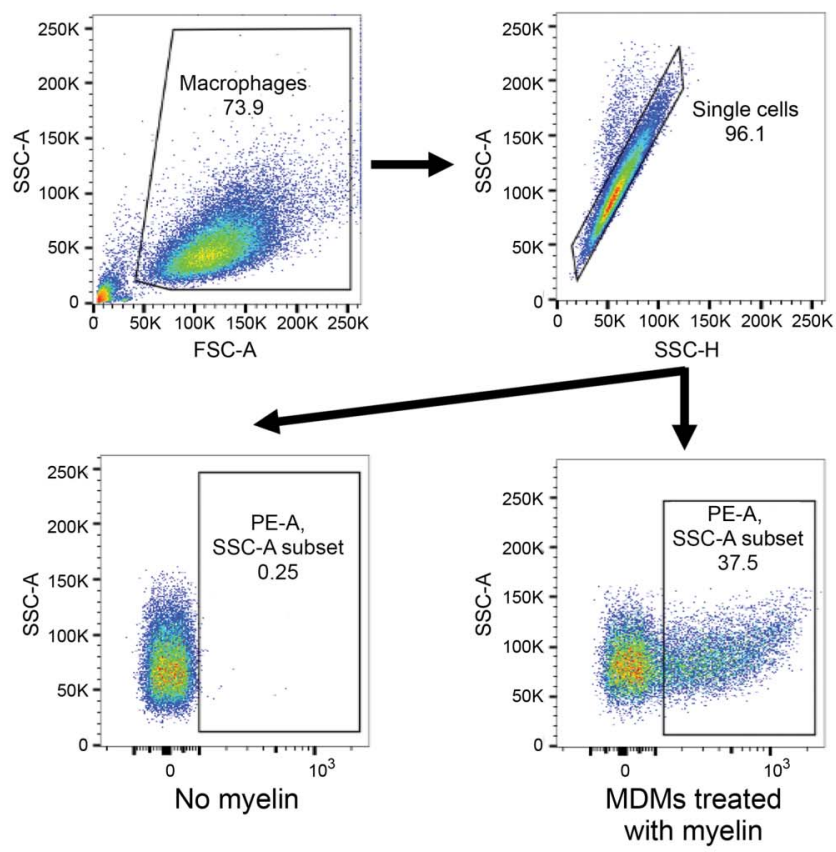

C

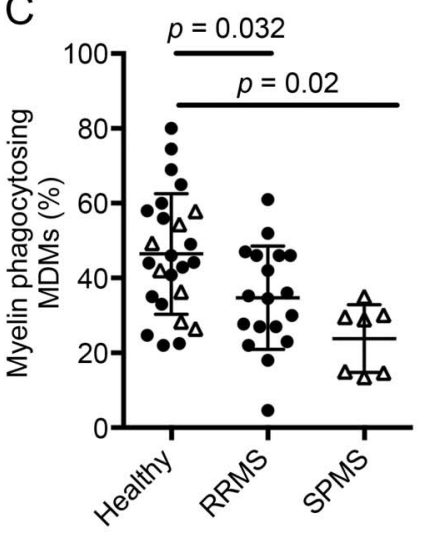

$\mathrm{D}$

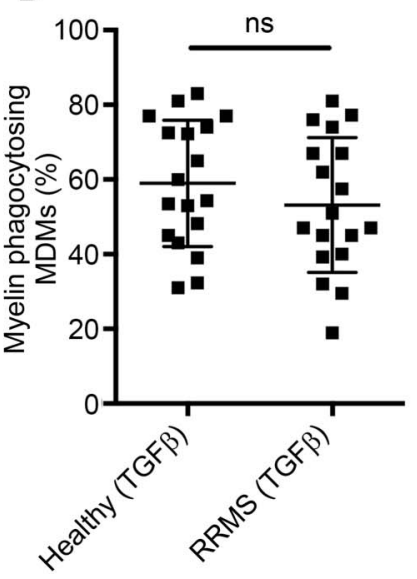

E

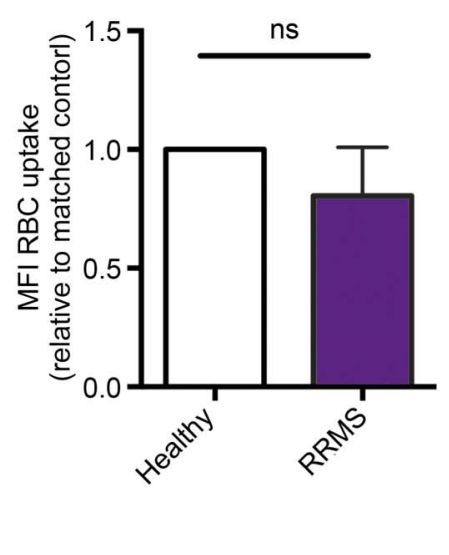

F

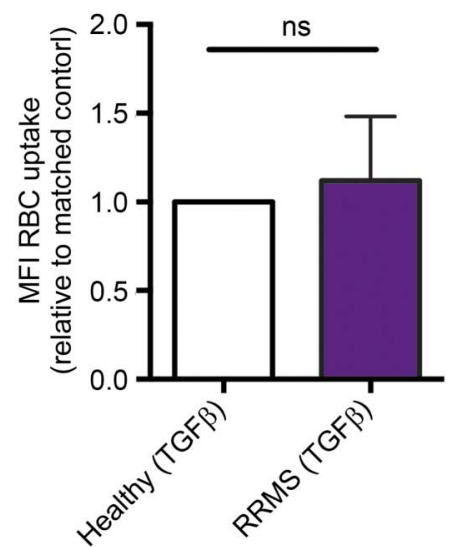

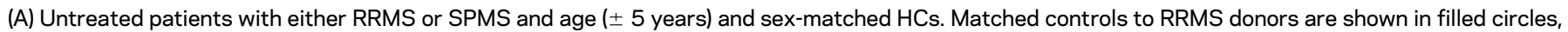

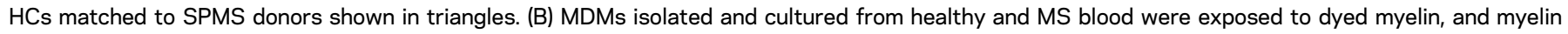

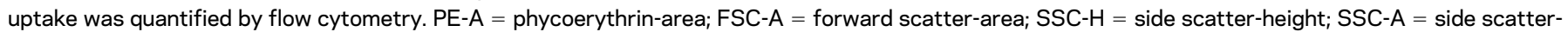

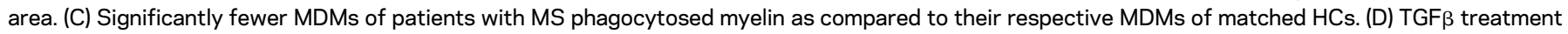

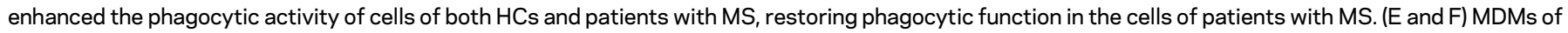

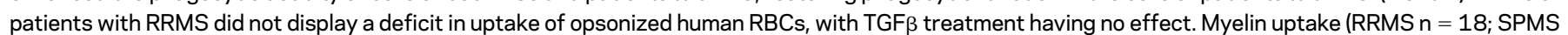

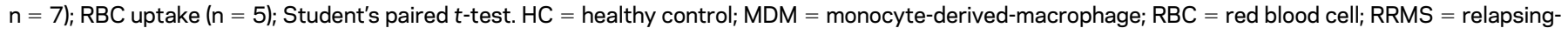
remitting MS; SPMS = secondary progressive MS; TGF $\beta=$ transforming growth factor $\beta$.

distinguishable (figure 1D). MDMs of patients with MS exhibited normal phagocytosis of opsonized human RBCs (figure 1E), which was not enhanced by TGF $\beta$ (figure 1F).

Reduced expression of MerTK and its ligand in MDMs of patients with MS can be restored by TGF $\beta$. messenger RNA (mRNA) levels of MerTK were significantly downregulated in patients with RRMS as compared to HCs (figure 2A) and were restored following TGF $\beta$ exposure (figure $2 \mathrm{~B}$ ), findings that were confirmed when assessing MerTK cell-surface protein expression prior to (figure 2C) and following (figure 2D) TGF $\beta$ exposure. Expression of the TAM receptor ligands Gas6 (figure 2E) and ProS (figure 2G) was also examined at the mRNA level. MDMs from patients with RRMS display significantly decreased levels of Gas6 expression, with levels of ProS expression comparable between the 2 populations. Expression of Gas6 in MDMs of untreated patients with MS was restored to HC levels following TGF $\beta$ exposure with TGF $\beta$ having no effect on ProS (figure 2, $\mathrm{F}$ and $\mathrm{H}$ ). 
A

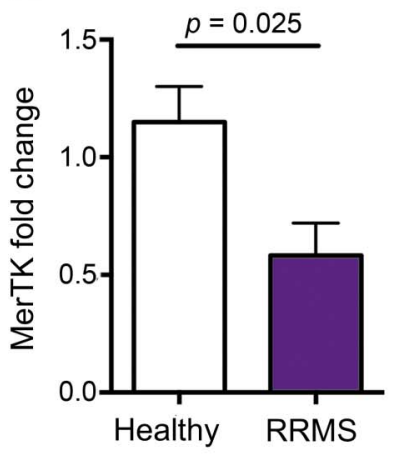

$\mathrm{E}$

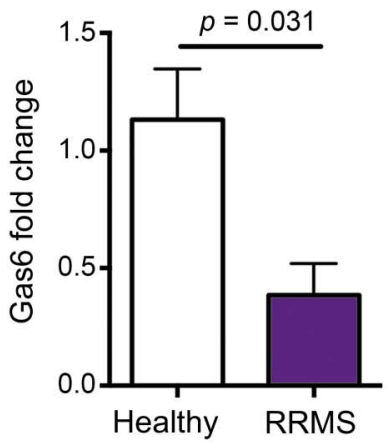

B

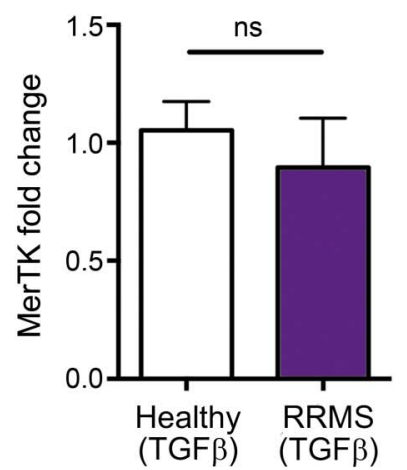

$\mathrm{F}$

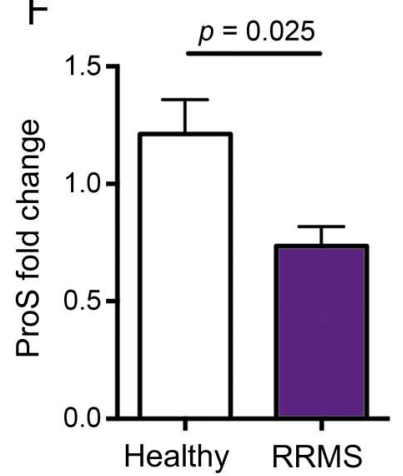

C

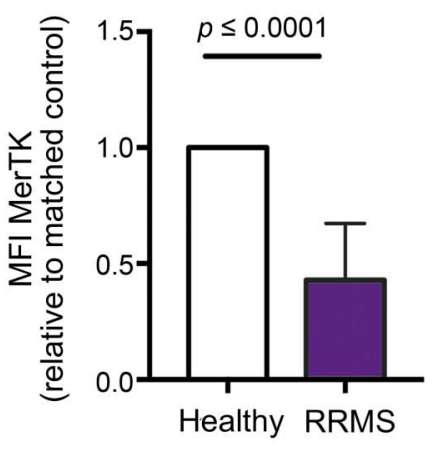

G

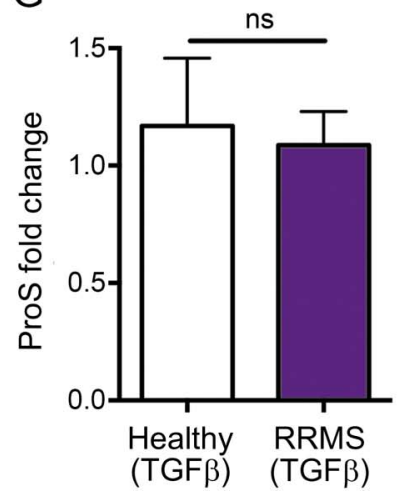

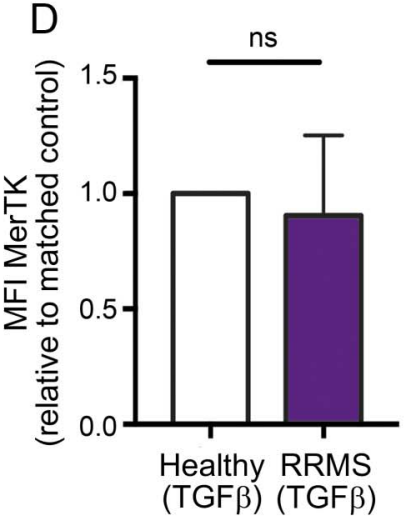

$\mathrm{H}$

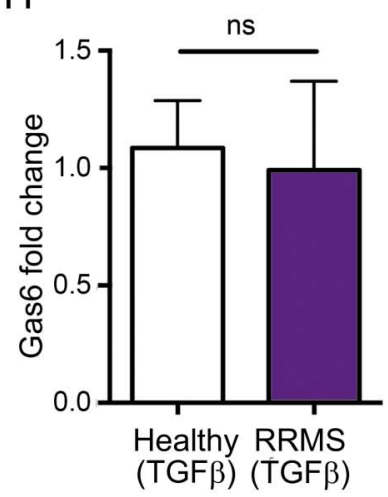

(A-D) MerTK mRNA and protein expression levels were found to be decreased in MDMs of patients with MS as compared to HC cells. Expression of MerTK was increased following treatment with TGF $\beta$ as compared to their untreated counterpart. (E-H) mRNA expression levels of MerTK ligands, Gas 6 and ProS, were also analyzed by quantitative PCR. Gas 6 but not ProS was found to be significantly decreased in MDMs of patients with MS with expression restored by TGF $\beta$ treatment in the MS cells. Protein expression presented as mean fluorescence intensity relative to matched controls ( $\mathrm{n}=16$ ). $\mathrm{mRNA}$ fold change was calculated using the $-\Delta \Delta$ threshold cycle method, relative to Gapdh (housekeeping gene; ns = not significant). $\mathrm{HC}=$ healthy control; MDM = monocytederived macrophage; mRNA = messenger RNA; RRMS = relapsing-remitting MS; TGF $\beta$ = transforming growth factor $\beta$.

Increased expression of TGF $\beta$ receptors in MS patientderived MDMs compared with HC cells. Expression of all 3 TGF $\beta$ receptors was significantly increased in monocytes of patients with MS as compared to $\mathrm{HC}$ monocytes (figure 3A). Expression of TGF $\beta R 1$ protein was examined by Western blotting and mirrored the mRNA expression profile with higher expression of TGF $\beta R 1$ in monocytes of patients with RRMS as compared to matched HCs. TGF- $\beta$ R 1 and 2 expression was also increased in MDMs of patients with MS (data not shown). Monocytes of healthy controls and patients with MS did not differ in expression of CD80, HLA-DR, CD274, and CCR7 (figure 3B).

MDMs of patients with MS are unable to adopt an antiinflammatory profile following myelin phagocytosis. To examine the consequence of reduced myelin uptake in these MDM populations, we measured interleukin 10 (IL-10) mRNA and protein expression following myelin uptake both in the presence and absence of TGF $\beta$. TGF $\beta$ increased IL-10 mRNA expression in both cell populations with myelin ingestion causing a significant increase in expression in MDMs of HCs but not in MDMs of RRMS (figure 4, A and B). This increase was inhibited following preincubation with the MerTK-specific antagonist (UNC2025) (figure 4A). IL-10 protein was measured by ELISA; MDMs of patients with RRMS release significantly less IL-10 protein following phagocytosis as compared to matched healthy donor cells.

Discussion In line with a recent study, we report a selective deficit in MS patient-derived MDMs to phagocytose myelin debris. ${ }^{13}$ We propose that this deficit is linked to an abnormal reduction in expression of the TAM receptor MerTK and its natural ligand as observed at both mRNA and protein levels. The MS MDM phagocytosis deficit could be rescued with exposure to TGF $\beta$, restoring both expression of the molecular machinery (MerTK and Gas6) necessary for the TAM receptor-mediated clearance of myelin, and, at the functional level, restoring the phagocytic ability of MDMs. 
A
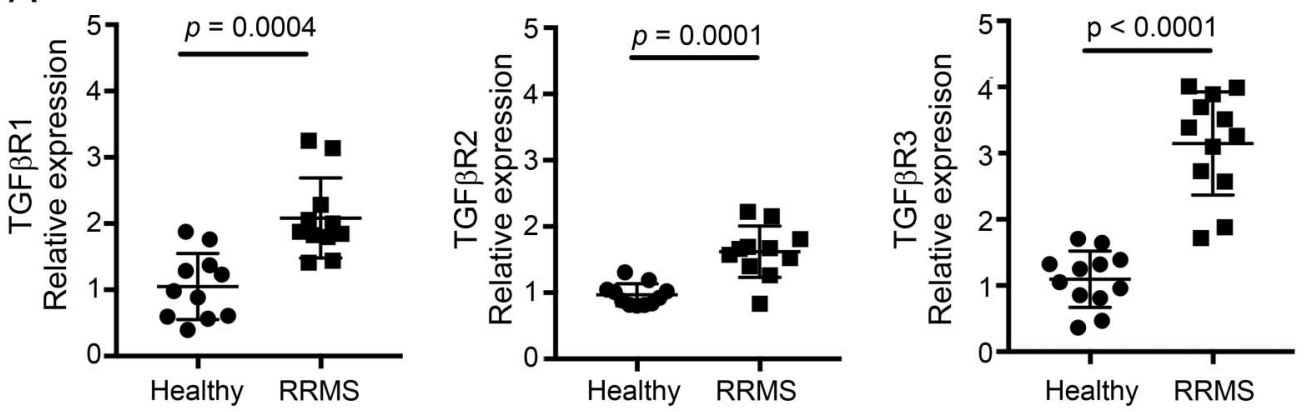

$\mathrm{B}$
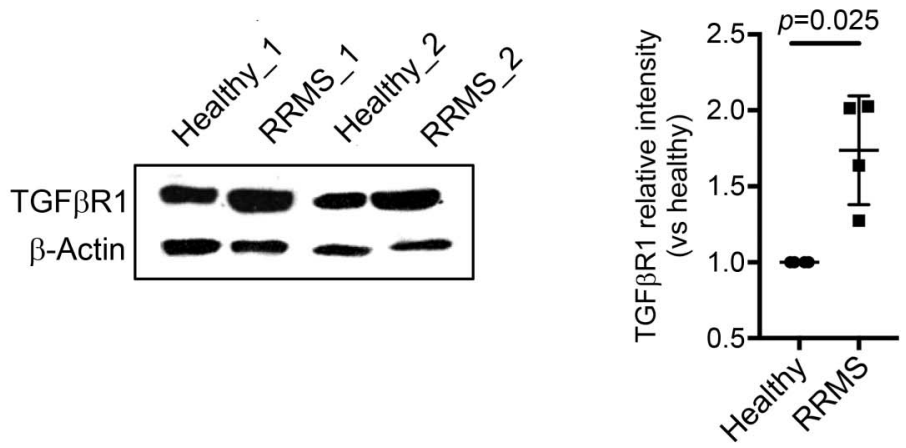

C
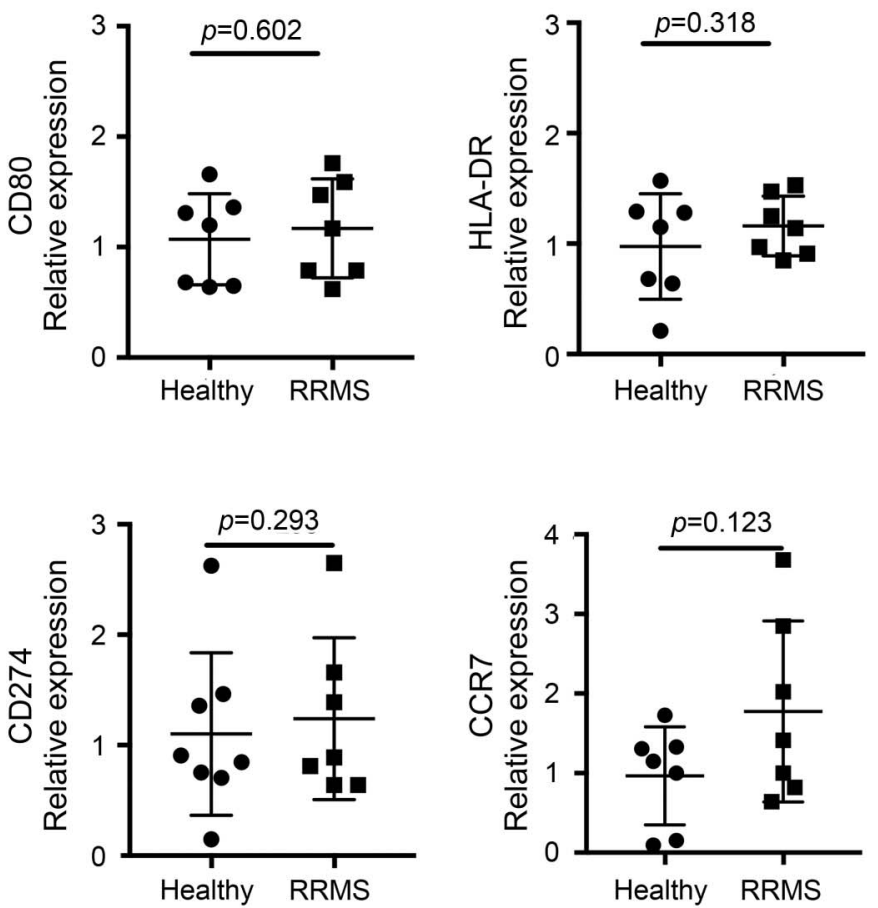

Expression of TGF $\beta$ receptors 1-3 was examined by quantitative PCR in freshly isolated monocytes of HCs (circle) and patients with MS (square). (A) Levels of all 3 receptors were significantly increased in MDMs of patients with MS as compared to matched controls. (B) Analysis of TGF $\beta R 1$ protein expression was performed by Western blotting, showing a significant reduction in expression in monocytes of patients with MS as compared to matched controls $(n=4)$. (C) Expression of known monocyte activation markers (CD80, HLA-DR, CD274, and CCR7) did not differ between monocytes of HCs and patients with MS. mRNA fold change was calculated using the $-\Delta \Delta$ threshold cycle method, relative to Gapdh (housekeeping gene). (A and B) Student's paired $t$-test. $\mathrm{HC}=$ healthy control; MDM = monocyte-derived macrophage; mRNA = messenger RNA; RRMS = relapsing-remitting MS; TGF $\beta$ = transforming growth factor $\beta$; TGF $\beta$ R1 = transforming growth factor, beta-receptor 1 .

We also observed that MDMs of HCs but not MDMs of patients with MS were able to upregulate expression of the anti-inflammatory cytokine, IL-10, following myelin ingestion. This reduced expression of IL-10 in cells of patients with MS may be due to their aforementioned reduced ability to phagocytose, which 
A

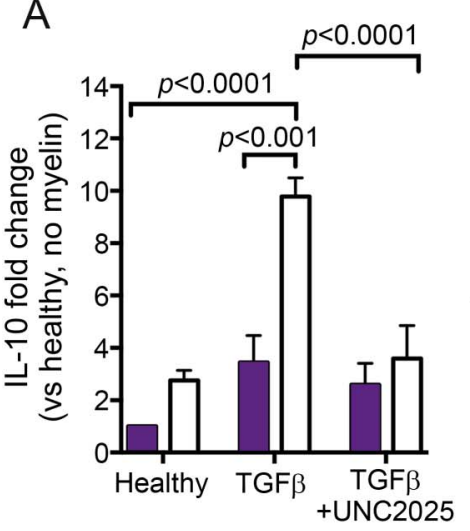

$\mathrm{B}$

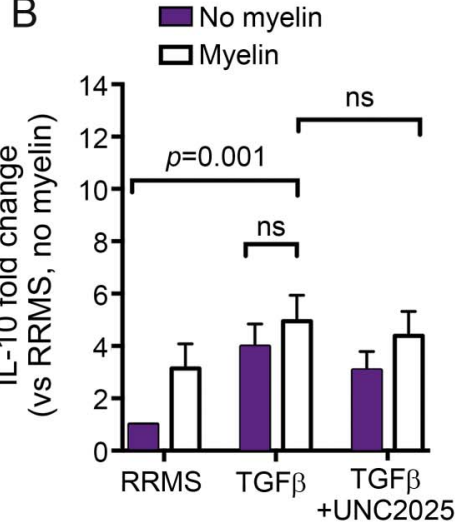

C

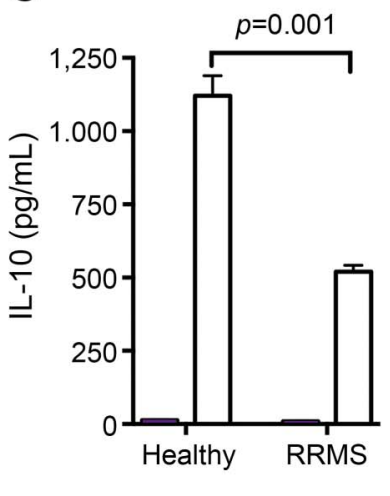

(A) IL-10 expression levels were analyzed in basal and TGF $\beta$-treated HC and MS patient MDMs following myelin exposure. TGF $\beta$-treated HC MDMs significantly increase expression of IL-10 following myelin uptake as compared to untreated cells. This IL-10 increase was inhibited by pretreatment with a MerTK-specific antagonist (UNC2025, $1 \mu \mathrm{M}$ ). (B) MDMs of patients with MS were unable to increase expression of IL-10 following myelin phagocytosis. (C) IL-10 protein was quantified by ELISA. mRNA fold change was calculated using the $-\Delta \Delta$ threshold cycle method, relative to Gapdh (housekeeping gene). (A and B) One-way analysis of variance and Tukey's multiple comparison post hoc test; ns = not significant. $\mathrm{HC}=$ healthy control; IL-10 = interleukin 10; MDM = monocyte-derived macrophage; mRNA = messenger RNA; RRMS = relapsing-remitting MS; TGF $\beta=$ transforming growth factor $\beta$.

has been shown to have an anti-inflammatory effect on macrophages and microglia. ${ }^{15,16}$ We previously showed that the MerTK-specific antagonist UNC2025 significantly inhibited IL-10 induction in MDMs of HCs..$^{5}$ Of note, the defective MS MDM phagocytosis did not appear to simply reflect an "activated" myeloid phenotype because their expression of classic activation markers was not increased, albeit a nonsignificant increase in the homing receptor CCR7 may reflect an enhanced ability of these cells to traffic to the CNS. ${ }^{17}$ Of interest, we observed increased expression of all 3 TGF $\beta$ receptors in MS patient-derived monocytes. TGF $\beta$ R1 in particular was seen to be upregulated at both mRNA and protein levels in monocytes of patients with RRMS. This contrasts with a decrease in expression of these receptors following exposure to classic pro-inflammatory activating stimuli such as lipopolysaccharide and interferon gamma (data not shown), again suggesting that these cells are not classically activated, "M1-skewed" cells. It is difficult to comment on whether our myeloid populations contain $\mathrm{CNS}$-experienced monocytes that have returned to the periphery; this increased expression of TGF $\beta$ receptors may be in response to either interaction with activated lymphoid cells in draining lymph nodes or possibly in response to blood-borne inflammatory markers reflecting the ongoing CNS pathology.

We previously reported that TGF $\beta$ can cause increased expression of MerTK and its ligands in both human MDMs and microglia. ${ }^{5}$ In the current study, activation of MDMs of patients with MS with TGF $\beta$ was able to overcome the functional abnormality in myelin phagocytosis, suggesting that this deficit could be targeted therapeutically. It is also reported that the decreased ability of MDMs of patients with MS to phagocytose myelin can be ameliorated by treatment with pioglitazone, an agonist for the nuclear receptor, peroxisome proliferator-activated receptor gamma (PPAR- $\gamma$ ) and its binding partner, the retinoid X receptor (RXR). ${ }^{13}$ Of interest, signaling via PPAR$\gamma$-RXR and other nuclear hormone receptors has been shown to induce MerTK expression that promoted the clearance of apoptotic bodies by dendritic cells. ${ }^{18-20}$

MerTK has been identified as a gene associated with increased MS susceptibility in 2 large, independent discovery and replication cohorts. ${ }^{11,12,21}$ Susceptibility single nucleotide polymorphisms in the MerTK gene were significantly associated with altered MerTK gene expression in purified monocytes but not in lymphocytes. ${ }^{12}$ Our study is not powered to resolve whether differences in myelin phagocytic activity reflect MerTK gene polymorphisms.

In the periphery, reduced myeloid cell expression of MerTK has been shown to directly affect the clearance of apoptotic lymphocytes in lymphoid organs. ${ }^{22}$ In TAM receptor knockout mice, this leads to a build-up of apoptotic cells in these structures causing swelling and leading to a broad spectrum of autoimmune disease, characterized by lymphocyte infiltration in most major organs and high titers of circulating auto-antibodies. ${ }^{23}$ This has a direct relevance to MS where defective T-cell tolerance can lead to expansion of self-reactive $\mathrm{T}$ cells. ${ }^{24}$

We described a molecular mechanism that underlies a selective, phagocytic deficit in macrophages 
generated from peripheral monocytes of untreated patients with MS. This reduced ability to phagocytose myelin involves decreased expression of MerTK and its ligand, Gas6, previously implicated in myelin phagocytosis by myeloid cells, and may be amenable to the therapeutic intervention.

\section{AUTHOR CONTRIBUTIONS}

L.M.H., J.P.A., and A.B.-O. conceived the project. L.M.H. designed the studies, performed the experiments, analysis, and data interpretation, and wrote the manuscript. J.H.J. and S.-Y.W. performed experiments and analysis of data. Y.H.L. performed experiments and proofread the manuscript. S.A. analyzed data. H.T. recruited patients. All authors critically revised the manuscript.

\section{ACKNOWLEDGMENT}

The authors acknowledge Manon Blain for providing technical assistance, and Rachel Vaughan and Dr. Gillian Muirhead for their help with patient recruitment. They also thank all patients who took part in this study.

\section{STUDY FUNDING}

This work was supported by a grant from the Multiple Sclerosis Society of Canada (MSSOC).

\section{DISCLOSURE}

L.M. Healy, S.-Y. Won, and Y.H. Lin report no disclosures. H. Toui received research support from the Canadian Multiple Sclerosis Society of Canada. S. Aljarallah reports no disclosures. A. Bar-Or served on the scientific advisory board for Receptos-Celgene, Roche/Genentech, Novartis, GSK, Guthy Jackson Greater Good Foundation, and Immune Tolerance Network; received travel funding and/or speaker honoraria from Receptos-Celegene, Roche/Genentech, Novartis, Sanofi-Genzyme, and GSK; served on the editorial board of Neurology and Clinical and Experimental Neuroimmunology; consulted for Receptos-Celgene, Roch/ Genentech, Novartis, and Sanofi-Genzyme, GSK; and received research support from Novartis and Genzyme-Sanofi. J.P. Antel served on the scientific advisory board for Sanofi-Aventis, Biogen IDEC, Novartis, and Celgene; received travel funding and/or speaker honoraria from Novartis, BiogenIdec, and Celgene; served on the editorial board of Multiple Sclerosis Journal, Journal of Neuroimmunology, and Journal of Neuroscience Research; received publishing royalties from the Oxford University Press; consulted for Novartis, Biogen Idec, Sanofi-Aventis, and Celgene; and received research support from Novartis, Revalesio, Mallincrodt, and the Multiple Sclerosis Society of Canada Medical Research Council-Great Britain. Go to Neurology.org/nn for full disclosure forms.

Received June 6, 2017. Accepted in final form August 9, 2017.

\section{References}

1. Lampron A, Larochelle A, Laflamme N, et al. Inefficient clearance of myelin debris by microglia impairs remyelinating processes. J Exp Med 2015;212:481-495.

2. Mishra MK, Yong VW. Myeloid cells — - targets of medication in multiple sclerosis. Nat Rev Neurol 2016;12:539-551.

3. Greenhalgh AD, Passos Dos Santos R, Zarruk JG, Salmon CK, Kroner A, David S. Arginase-1 is expressed exclusively by infiltrating myeloid cells in CNS injury and disease. Brain Behav Immun 2016;56:61-67.

4. Michell-Robinson MA, Touil H, Healy LM, et al. Roles of microglia in brain development, tissue maintenance and repair. Brain 2015;138:1138-1159.

5. Healy LM, Perron G, Won SY, et al. MerTK is a functional regulator of myelin phagocytosis by human myeloid cells. J Immunol 2016;196:3375-3384.
6. Zizzo G, Hilliard BA, Monestier M, Cohen PL. Efficient clearance of early apoptotic cells by human macrophages requires M2c polarization and MerTK induction. J Immunol 2012;189:3508-3520.

7. van der Meer JH, van der Poll T, van 't Veer C. TAM receptors, Gas6, and protein S: roles in inflammation and hemostasis. Blood 2014;123:2460-2469.

8. Quarles RH. Comparison of CNS and PNS myelin proteins in the pathology of myelin disorders. J Neurol Sci 2005;228:187-189.

9. Lemke G. Biology of the TAM receptors. Cold Spring Harb Perspect Biol 2013;5:1-17.

10. Rothlin CV, Carrera-Silva EA, Bosurgi L, Ghosh S. TAM receptor signaling in immune homeostasis. Annu Rev Immunol 2015;33:355-391.

11. Ma GZ, Stankovich J, Australia, et al. Polymorphisms in the receptor tyrosine kinase MERTK gene are associated with multiple sclerosis susceptibility. PLoS one 2011;6: e16964.

12. Binder MD, Fox AD, Merlo D, et al. Common and low frequency variants in MERTK are independently associated with multiple sclerosis susceptibility with discordant association dependent upon HLA-DRB1*15:01 status. PLoS Genet 2016;12:e1005853.

13. Natrajan MS, Komori M, Kosa P, et al. Pioglitazone regulates myelin phagocytosis and multiple sclerosis monocytes. Ann Clin Transl Neurol 2015;2:1071-1084.

14. Norton WT, Poduslo SE. Myelination in rat brain: method of myelin isolation. J Neurochem 1973;21:749-757.

15. Bogie JF, Jorissen W, Mailleux J, et al. Myelin alters the inflammatory phenotype of macrophages by activating PPARs. Acta Neuropathol Commun 2013;1:43.

16. Liu Y, Hao W, Letiembre M, et al. Suppression of microglial inflammatory activity by myelin phagocytosis: role of p47-PHOX-mediated generation of reactive oxygen species. J Neurosci 2006;26:12904-12913.

17. Nuyts AH, Ponsaerts P, Van Tendeloo VF, et al. Except for C-C chemokine receptor 7 expression, monocytederived dendritic cells from patients with multiple sclerosis are functionally comparable to those of healthy controls. Cytotherapy 2014;16:1024-1030.

18. Zagorska A, Traves PG, Lew ED, Dransfield I, Lemke G. Diversification of TAM receptor tyrosine kinase function. Nat Immunol 2014;15:920-928.

19. Mukundan L, Odegaard JI, Morel CR, et al. PPAR-delta senses and orchestrates clearance of apoptotic cells to promote tolerance. Nat Med 2009;15:1266-1272.

20. Gonzalez N, Bensinger SJ, Hong C, et al. Apoptotic cells promote their own clearance and immune tolerance through activation of the nuclear receptor LXR. Immunity 2009;31:245-258.

21. International Multiple Sclerosis Genetics Consortium. Genetic risk and a primary role for cell-mediated immune mechanisms in multiple sclerosis. Nature 2011;476: 214-219.

22. Scott RS, McMahon EJ, Pop SM, et al. Phagocytosis and clearance of apoptotic cells is mediated by MER. Nature 2001;411:207-211.

23. Lu Q, Lemke G. Homeostatic regulation of the immune system by receptor tyrosine kinases of the Tyro 3 family. Science 2001;293:306-311.

24. Goverman JM. Immune tolerance in multiple sclerosis. Immunol Rev 2011;241:228-240. 


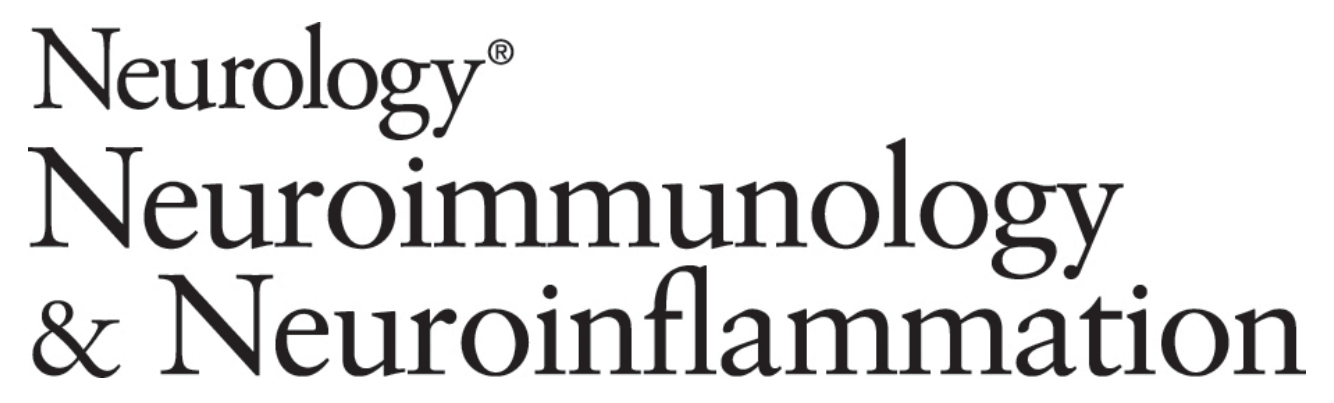
MerTK-mediated regulation of myelin phagocytosis by macrophages generated from patients with MS
Luke M. Healy, Jeong Ho Jang, So-Yoon Won, et al.
Neurol Neuroimmunol Neuroinflamm 2017;4;
DOI 10.1212/NXI.0000000000000402

This information is current as of October 16, 2017

Neurol Neuroimmunol Neuroinflamm is an official journal of the American Academy of Neurology.

Published since April 2014, it is an open-access, online-only, continuous publication journal. Copyright

Copyright $\odot 2017$ The Author(s). Published by Wolters Kluwer Health, Inc. on behalf of the American

Academy of Neurology.. All rights reserved. Online ISSN: 2332-7812.

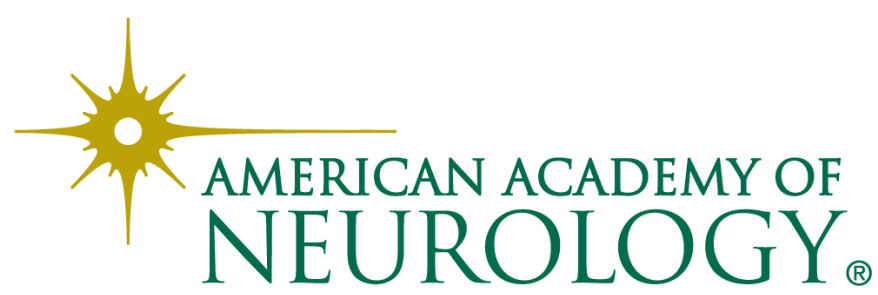




\section{Updated Information \& Services}

References

Citations

Subspecialty Collections

Permissions \& Licensing

Reprints including high resolution figures, can be found at: http://nn.neurology.org/content/4/6/e402.full.html

This article cites 24 articles, 6 of which you can access for free at: http://nn.neurology.org/content/4/6/e402.full.html\#\#ref-list-1

This article has been cited by 1 HighWire-hosted articles: http://nn.neurology.org/content/4/6/e402.full.html\#\#otherarticles

This article, along with others on similar topics, appears in the following collection(s):

All Clinical Neurology

http://nn.neurology.org//cgi/collection/all_clinical_neurology All Demyelinating disease (CNS)

http://nn.neurology.org//cgi/collection/all_demyelinating_disease_cns All Immunology

http://nn.neurology.org//cgi/collection/all_immunology

Autoimmune diseases

http://nn.neurology.org//cgi/collection/autoimmune_diseases

Multiple sclerosis

http://nn.neurology.org//cgi/collection/multiple_sclerosis

Information about reproducing this article in parts (figures,tables) or in its entirety can be found online at:

http://nn.neurology.org/misc/about.xhtml\#permissions

Information about ordering reprints can be found online:

http://nn.neurology.org/misc/addir.xhtml\#reprintsus

Neurol Neuroimmunol Neuroinflamm is an official journal of the American Academy of Neurology.

Published since April 2014, it is an open-access, online-only, continuous publication journal. Copyright

Copyright $\odot 2017$ The Author(s). Published by Wolters Kluwer Health, Inc. on behalf of the American

Academy of Neurology.. All rights reserved. Online ISSN: 2332-7812.

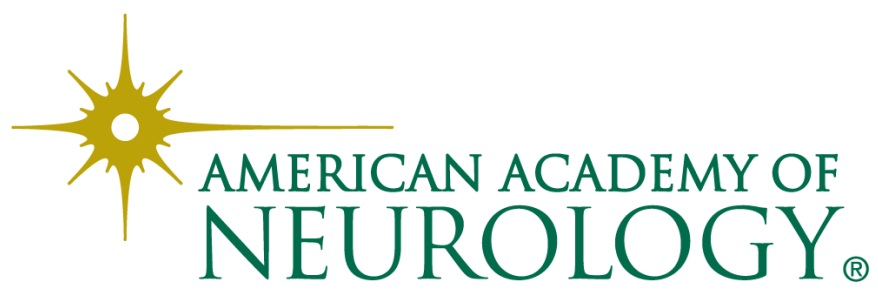

